\title{
RANCANG BANGUN COMPANY PROFILE GABUNGAN PERUSAHAAN KONSTRUKSI NASIONAL INDONESIA (GAPEKSINDO) BERBASIS WEB
}

\author{
Wiwik Widiyatni ${ }^{1}$, Vilianty Rafida ${ }^{2}$ Ita $_{\text {Arfyanti }}{ }^{3}$ \\ STMIK Widya Cipta Dharma ${ }^{1,2,3}$ \\ JL. Prof. M. Yamin No. 25 Samarinda \\ Sur-el : wiwik@wicida.ac.id ${ }^{1}$, vily@wicida.ac.id ${ }^{2}$, ita@wicida.ac.id ${ }^{3}$
}

\begin{abstract}
Research on Web-based Company Profile Design of the Association of Indonesian Construction Companies (GAPEKSINDO) is a research to make it easier for people to obtain complete and up-to-date information because information is considered very important in decision making and in achieving goals. In addition to obtaining complete and up-to-date information, the website can also send and publish information to the wider community online. The system development method used in this research is the System Development Life Cycle (SDLC) method, or better known as the system development life cycle in system engineering and software engineering, is the process of making and changing systems and the models and methodologies used to develop these systems. The research results are expected that this system can publish its activities for more up-to-date information so that the public can find out about the activities that have been carried out, the ease of information about GAPEKSINDO.
\end{abstract}

Keywords: Website Profile, SDLC, GAPEKSINDO, Information

\begin{abstract}
Abstrak : Penelitian Rancang Bangun Company Profile Gabungan Perusahaan Konstruksi Nasional Indonesia (GAPEKSINDO) berbasis Web merupakan penelitian untuk mempermudah masyarakat memperoleh informasi yang lengkap dan terbaru karena informasi di rasa sangat penting dalam pengambilan keputusan dan dalam mencapai tujuan. Selain memperoleh informasi yang lengkap dan terbaru, website juga dapat mengirim serta mempublikasikan informasi kepada masyarakat luas secara online. Metode Pengembangan sistem yang digunakan penelitian yaitu metode (SDLC) System Development Life Cycle atau yang lebih dikenal siklus hidup pengembangan sistem dalam rekayasa sistem dan rekayasa perangkat lunak adalah proses pembuatan dan pengubahan sistem serta model dan metodologi yang digunakan untuk mengembangkan sistem-sistem tersebut. Hasil penelitian diharapkannya sistem ini dapat mempublikasikan kegiatannya untuk informasi yang lebih terbaru lagi sehingga masyarakat dapat mengetahui kegiatan-kegiatan yang telah dilakukan, kemudahan informasi tentang GAPEKSINDO.
\end{abstract}

Kata kunci: Website Profile, SDLC, GAPEKSINDO, Informasi

\section{PENDAHULUAN}

Arus informasi di era modern ini sangatlah cepat menyebar ke segala penjuru dunia. Informasi menyebar melalui media yang bermacam-macam dan dalam bentuk yang berbeda-beda. Secara umum bentuk informasi bisa berupa gambar, suara, maupun video[1].
Salah satu media penyebaran informasi yang sangat cepat yaitu internet. Informasi disampaikan melalui sebuah portal yang disebut dengan website. Website adalah sebuah portal yang bisa diakses melalui internet dari mana saja dan kapan saja. Hampir setiap instansi atau lembaga di seluruh dunia sudah mempunyai website sebagai sarana komunikasi antara perusahaan dengan pelanggan[2]. 
Gabungan Perusahaan Konstruksi Nasional Indonesia (GAPEKSINDO) Provinsi Kalimantan Timur mempunyai salah satu Masalah yaitu menyangkut tentang penyajian informasi untuk mengetahui informasi dari pelayanan yang disediakan. Salah satu faktor untuk membangun website company profile pada Gabungan Rekanan Konstruksi Indonesia agar dapat mempermudah calon klien dari dalam maupun luar Samarinda untuk mengetahui informasi dari pelayanan yang disediakan.

Dengan membuat company profile berbasis web, akan lebih dimudahkan untuk akses informasi dan lebih banyak merangkum informasi dibandingkan dengan brosur, pamphlet ataupun surat kabar. Selain itu kemudahan akses menjadi keuntungan sendiri untuk company profile berbasis web, sebab di era sekarang konsumen lebih banyak mencari sesuatu lewat internet[3]. Company profile berbasis web lebih lebih inovatif dibandingkan dengan company profile berbasis cetak sebab adanya company profile ini para konsumen dapat mudah mengakses kapan dan di manapun selama terdapat jaringan internet sehingga lebih menguntungkan bagi pihak perusahaan[4].

\section{METODOLOGI PENELITIAN}

Metode penelitian dalam peningkatan pelayanan jasa konsultan lingkungan hidup dengan pengembangan website CV Fahmi Jaya adalah sebagai berikut:

\subsection{Informasi}

Informasi adalah data yang telah diklasifikasi atau diolah atau diinterpretasikan untuk digunakan dalam proses pengambilan keputusan[5]. Informasi merupakan hasil olah data, di mana data tersebut sudah diproses dan diinterpretasikan menjadi suatu pengetahuan yang bermakna untuk pengambilan keputusan [6].

\subsection{Web}

Website atau situs web merupakan sebutan bagi sekelompok halaman web (web page). Sebuah situs web diakses dari sebuah URL (Uniform Resource Locator) yang menjadi “akar” (root)[7].

\subsection{Internet}

Internet adalah suatu media informasi komputer global yang dapat di katakana sebagai teknologi tercanggih abad ini[8]. Secara etimologis, Internet berasal dari Bahasa Inggris, yakni inter berarti antar dan net berarti jaringan sehingga dapat kita artikan hubungan antar jaringan[9].

\subsection{Basis Data (Database)}

Berikut beberapa Pengertian tentang Basis data, yaitu:

1. Kumpulan terpadu dari elemen data logis yang saling berhubungan Basis Data Mengkonsolidasikan banyak catatan yang sebelumnya disimpan dalam file terpisah.

2. Merupakan suatu kumpulan data yang behubungan secara logis dengan deskripsi data tersebut, yang dirancang untuk memenuhi informasi yang dibutuhkan oleh suatu organisasi. Artinya, basis data merupakan tempat penyimpanan data yang besar, di mana 
dapat digunakan oleh banyak pengguna [10]. Seluruh item basis data tidak lagi dimiliki oleh satu departemen, merupakan menjadi sumber daya perusahaan yang dapat digunakan bersama[11].

\subsection{MySQL}

MySQL atau dibaca "Myskuel" dengan adalah suatu RDBMS (Relational Data Base Management System) yaitu aplikasi sistem yang menjalakan fungsi pengolahan data. MySQL pertama dikembangkan oleh MySQL AB yang kemudian diakuisisi Sun Microsystem dan terakhir dikelola oleh Oracle Corporation [12].

\subsection{Tahapan Pengembangan Sistem}

Metode pengembangan sistem yang digunakan dalam penelitian adalah sebagai berikut:

\section{Waterfall}

"Metodologi Pengembangan Sistem adalah metode-metode, prosedur konsep pekerjaan, aturan-aturan dan postulat-postulat yang digunakan untuk mengembangkan suatu sistem informasi”[2]. Pengembangan sistem didefinisikan sebagai aktivitas untuk menghasilkan sistem informasi berbasis komputer untuk menyelesaikan persoalan (problem) organisasi atau memanfaatkan kesempatan (opportunities) yang timbul. Siklus Waterfall pada gambar 1, biasa juga disebut siklus hidup perangkat lunak [13]. Mengambil kegiatan dasar seperti spesifikasi, pengembangan, validasi, dan evolusi dan merepresentasikannya sebagai fase-fase proses yang berbeda seperti spesifikasi persyaratan, perancangan perangkat lunak, implementasi, pengujian dan seterusnya[14].

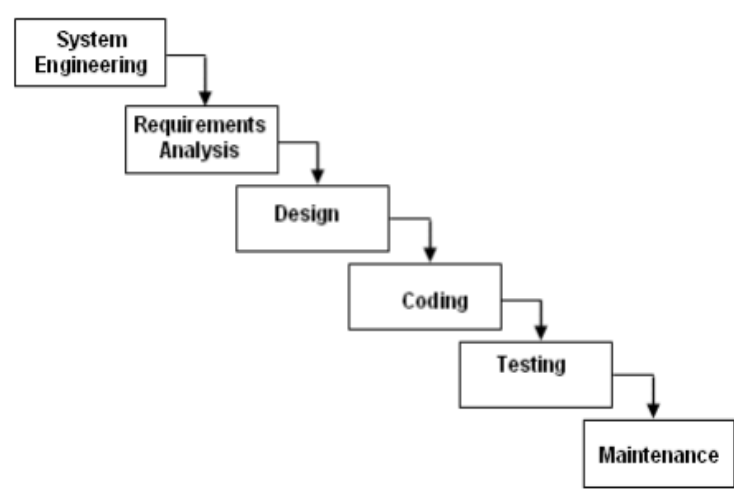

\section{Gambar 1. Gambar model Waterfall}

2. Analisis

Pada tahap ini dilakukan analisis terhadap aplikasi atau sistem yang akan dibangun berikut ini adalah beberapa analisis yang perlu dilakukan dalam membangun Company Profile Gabungan Perusahaan Konstruksi Nasional Indonesia (GAPEKSINDO) berbasis Web:

1) Use Case Diagram (User)

Pada Gambar 2. use case diagram ini dapat dilihat fungsionalitas sistem yang ada pada website company profile. Pada use case ini digambarkan bagaimana kemampuan website, di mana user dapat memilih menu-menu yang disediakan di dalam website. Berikut adalah diagram use case user pada website company profile GAPEKSINDO. 


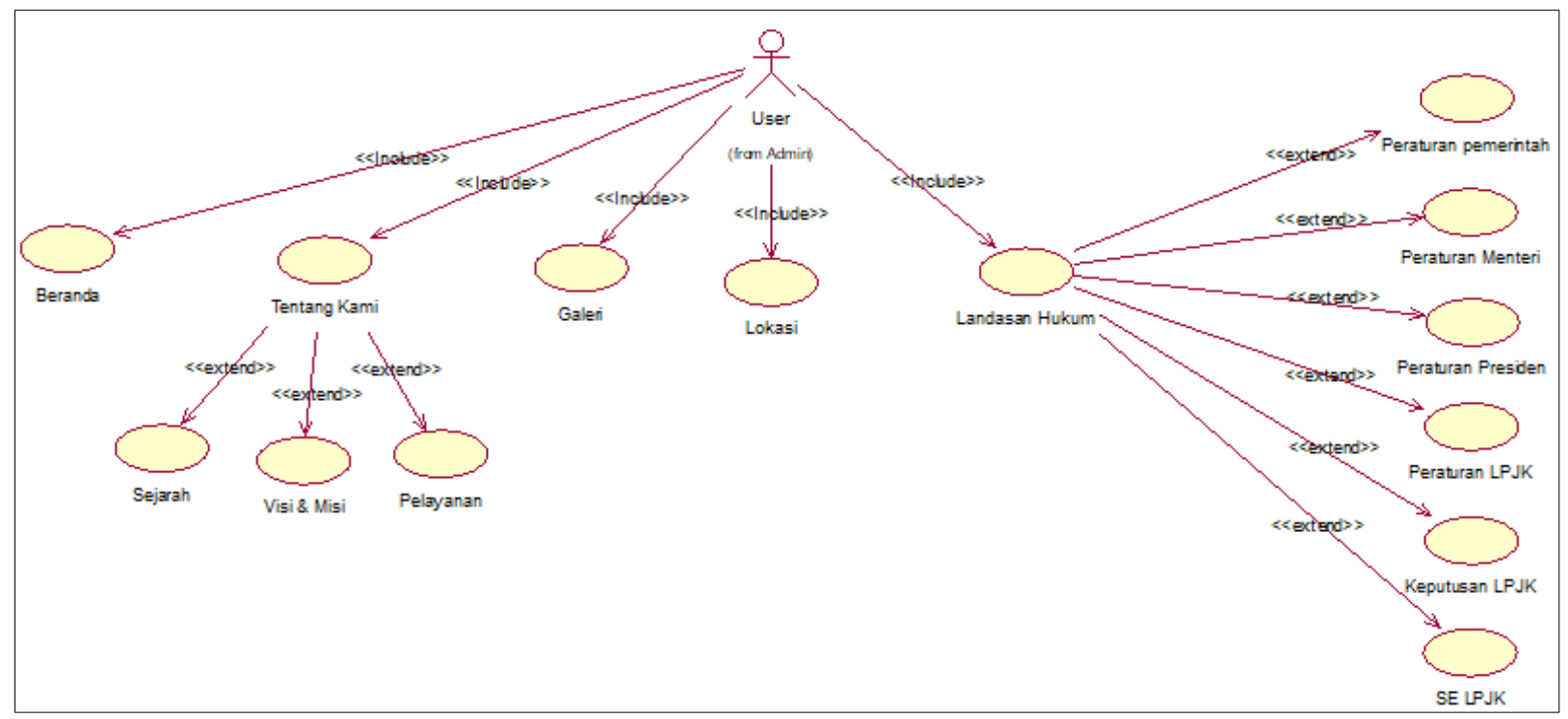

\section{Gambar 2. Diagram Use Case User}

\section{2) Use Case Diagram (Admin)}

Pada Gambar 3. Menampilkan use case diagram beranda pada website admin. Di mana admin dapat memilih menu-menu yang disediakan di dalam website.

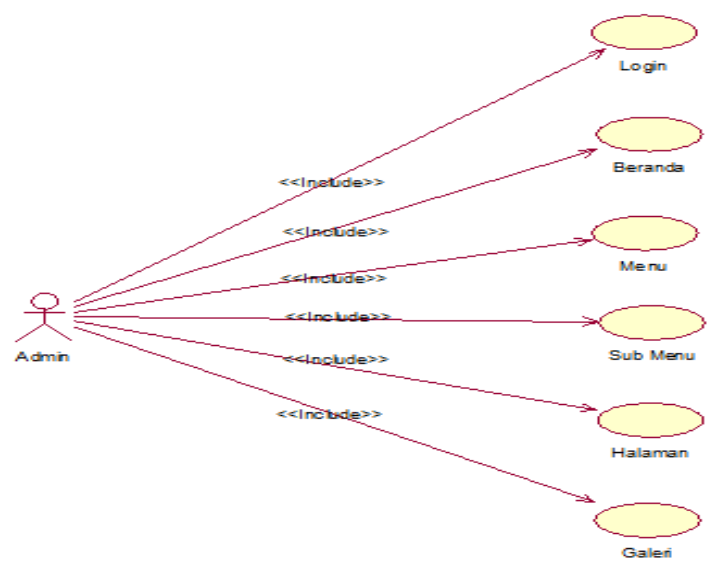

3) Activity Diagram Beranda (User)

Pada gambar 4. Menampilkan activity diagram beranda pada website user.

4) Activity Diagrm Beranda (Admin)

Pada Gambar 5. Menampilkan activity diagram beranda pada website admin.

5) Sequence Diagram Beranda (User)

Pada Gambar 6. Menampilkan sequence diagram beranda pada website user.

6) Sequence Diagram Beranda (Admin)

Pada Gambar 7. Menampilkan sequence diagram beranda pada webwite admin.

\section{Gambar 3. Diagram Use Case Admin}

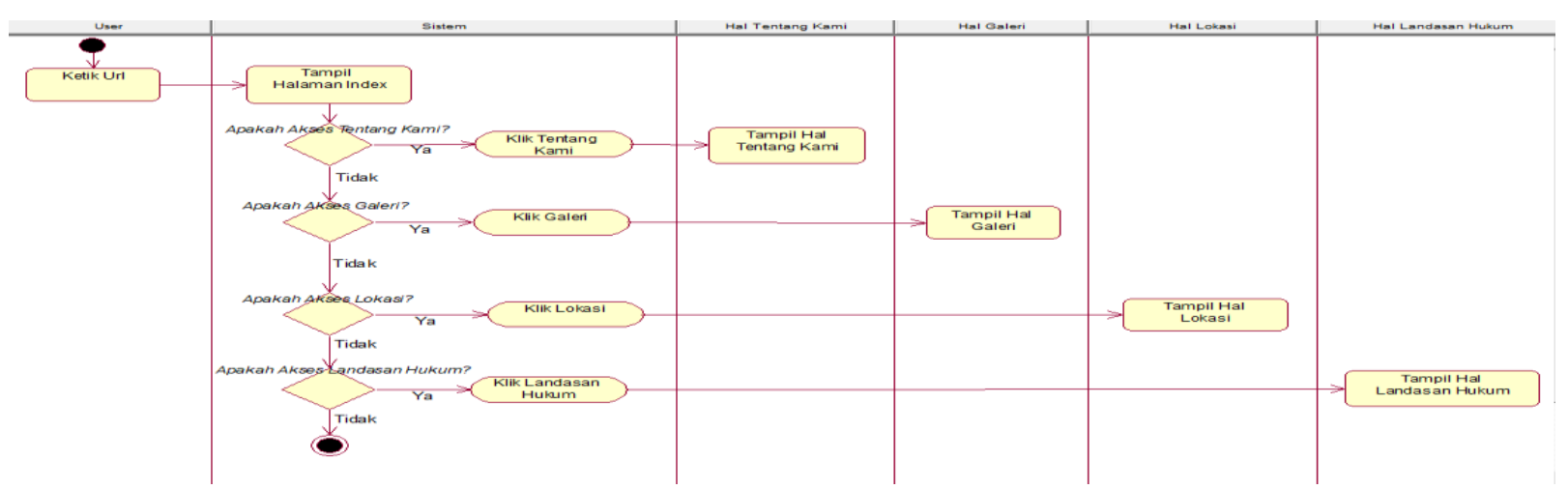

Gambar 4. Activity Diagram Beranda User 


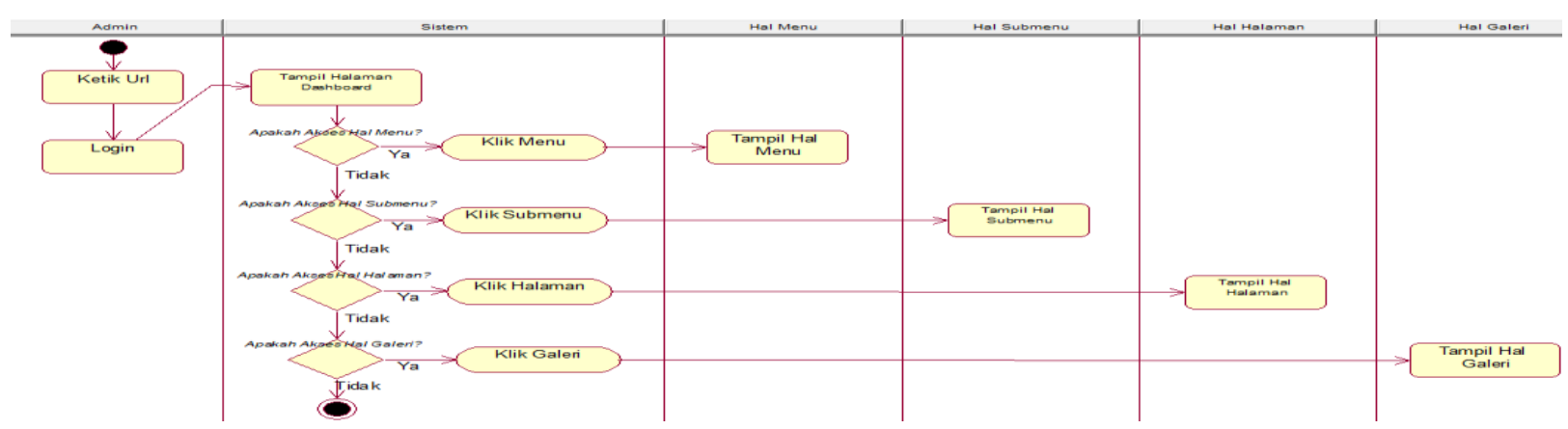

Gambar 5. Activity Diagrm Beranda Admin

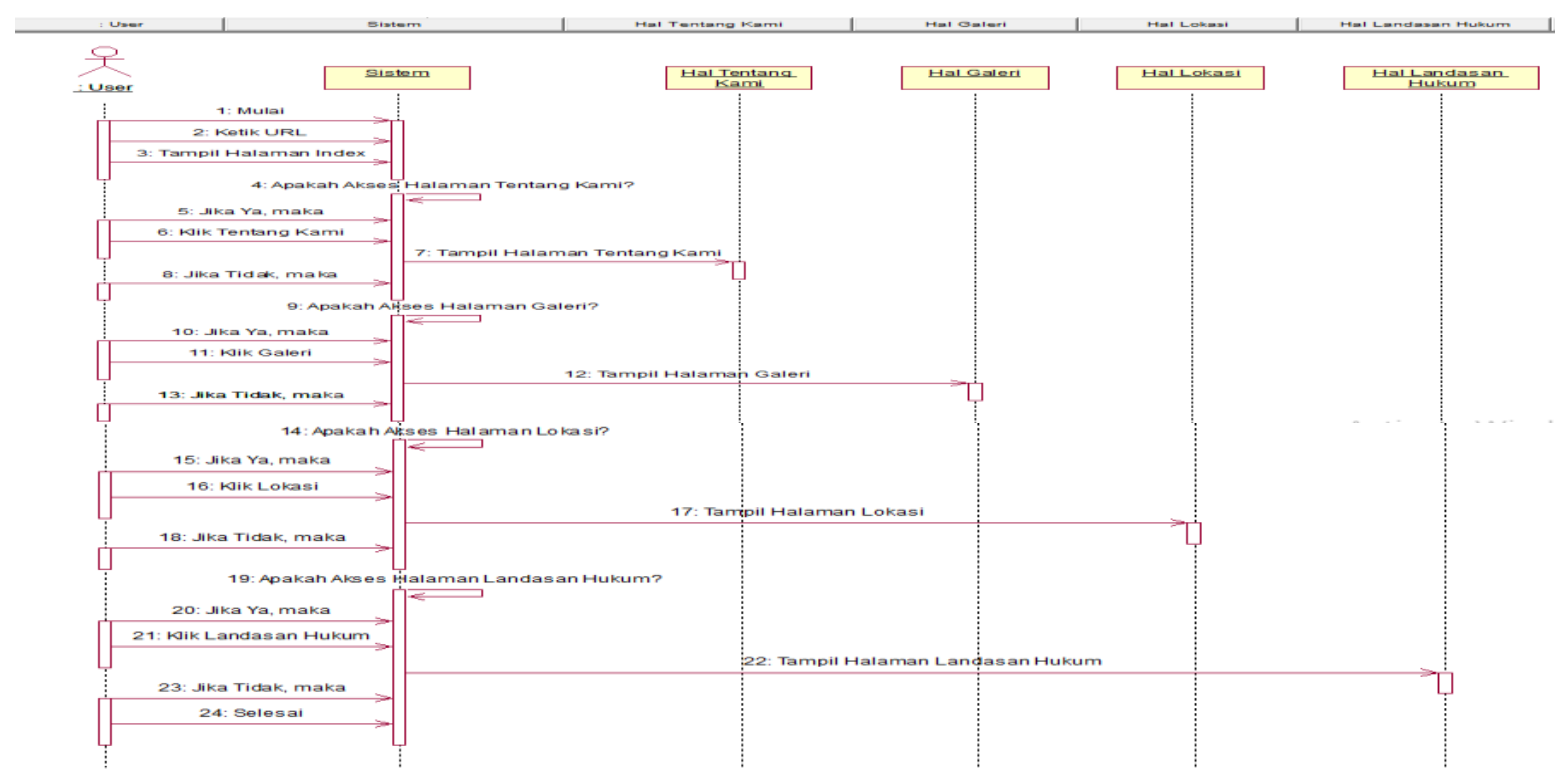

Gambar 6. Sequence Diagram Beranda User

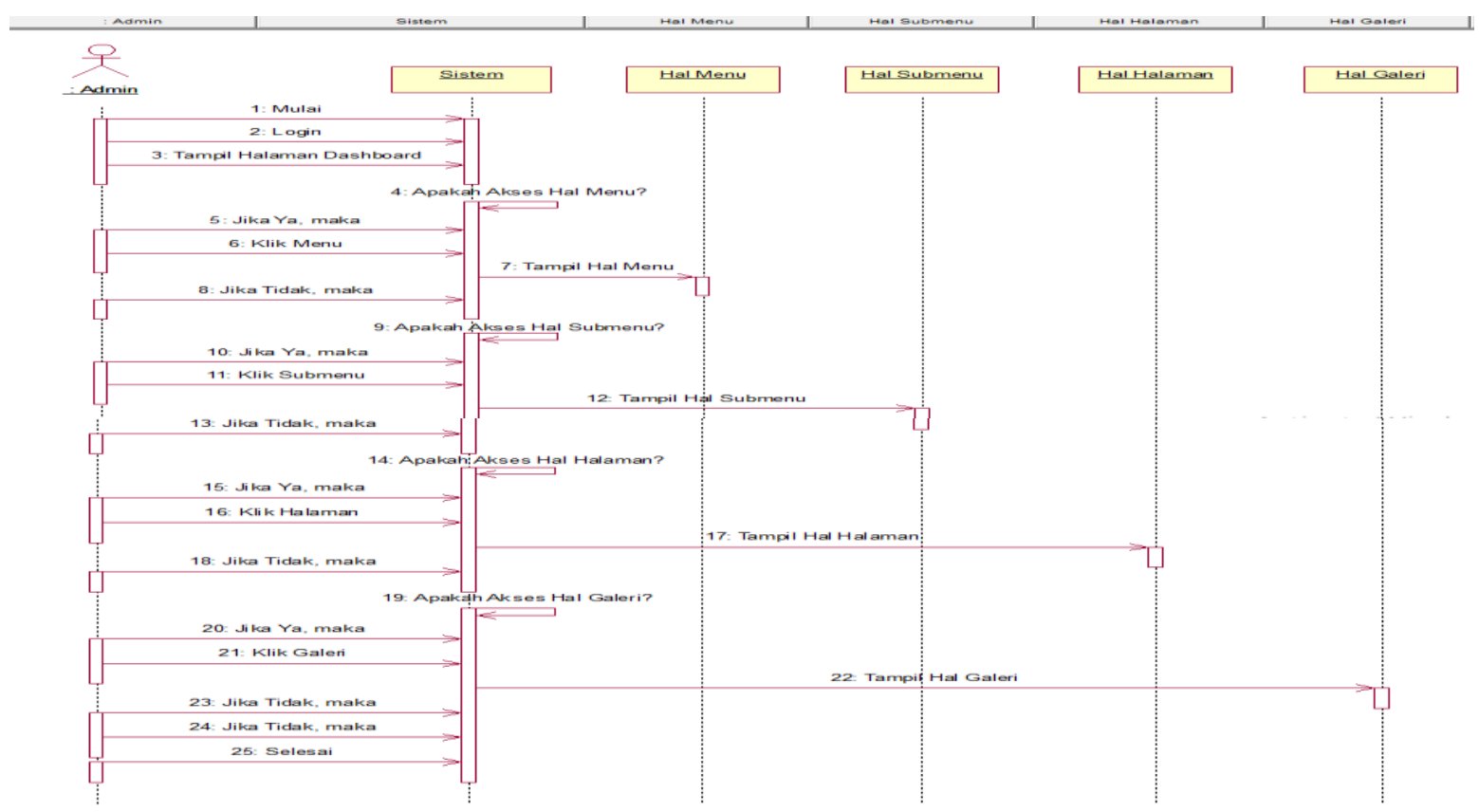

Gambar 7. Sequence Diagram Beranda Admin

Rancang Bangun Company Profile Gabungan Perusahaan Konstruksi Nasional Indonesia ... ... 


\section{HASIL DAN PEMBAHASAN}

Pada Gambar 8. yaitu halaman utama yang dapat dilihat pengunjung. Pada halaman ini merupakan proses awal untuk dapat mengakses pada halaman index pengunjung berikutnya dalam halaman index pengunjung ini terdapat informasiinformasi yang di update oleh admin, sehingga pengunjung mengetahui berita atau informasi terbaru tentang GAPEKSINDO.
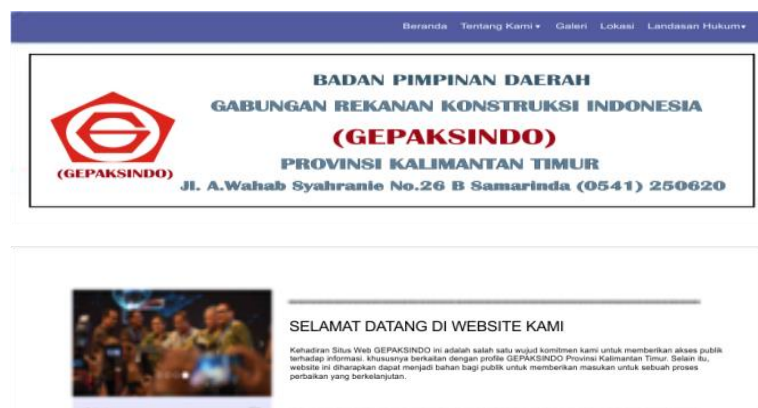

SELAMAT DATANG DI WEBSITE KAMI

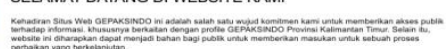

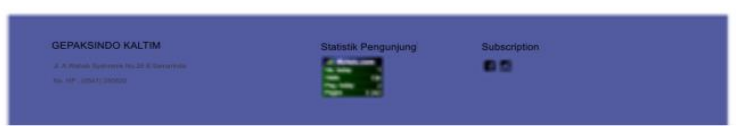

Gambar 8. Halaman Utama Website

Pada Gambar 9. Menampilkan tentang visi dan misi dari GAPEKSINDO. Sehingga pengunjung mengetahui informasi visi dan misi dari GAPEKSINDO.

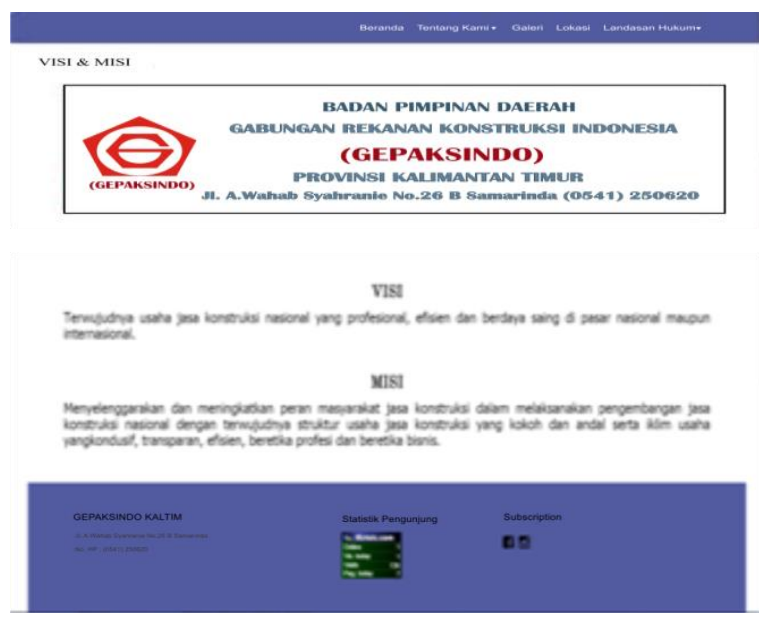

Gambar 9. Halaman Visi dan Misi
Pada Gambar 10. Menampilkan tentang form yang dapat di kunjungi oleh admin utama GAPEKSINDO. Di mana admin dapat melakukan semua kegiatan pada halaman website seperti halnya meng-update informasi, foto-foto serta menambah data, menghapus, edit dan lain-lain.

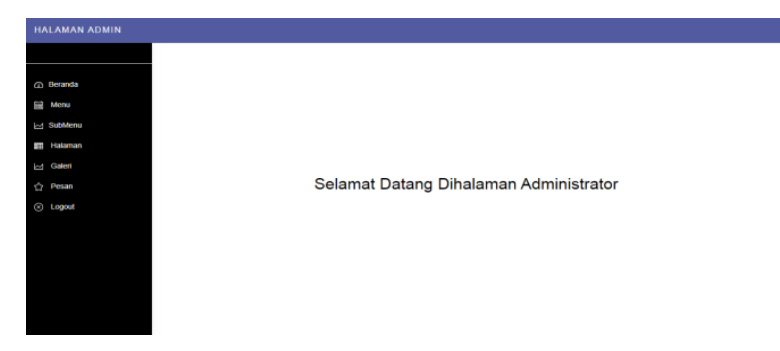

\section{Gambar 10. Halaman Utama Admin}

\section{KESIMPULAN}

Dengan adanya website ini, informasi mengenai GAPEKSINDO dapat diketahui banyak orang baik dari Samarinda maupun luar kota dan dengan demikian informasi dapat dilihat oleh semua orang serta mendapatkan informasi terbaru pada GAPEKSINDO.

Pada website ini pengunjung dapat memberikan komentar atau saran mengenai pelayanan atau apapun yang berhubungan dengan GAPEKSINDO.

Diharapkan juga adanya pengembangan terhadap website ini agar dapat menjadi sebuah website yang lebih lengkap lagi, yang dapat memudahkan pengunjung untuk mendapatkan informasi dan memberikan minat dari pengunjung yang ingin mendapatkan informasi mengenai GAPEKSINDO. 


\section{UCAPAN TERIMA KASIH}

Publikasi ini dibiayai oleh Direktorat Riset dan Pengabdian Masyarakat Direktorat Jenderal Penguatan Riset dan Pengembangan Kementerian Riset dan Teknologi/ Badan Riset dan Inovasi Nasional sesuai dengan Kontrak Penelitian Tahun Anggaran 2021.

\section{DAFTAR PUSTAKA}

[1] Abdulloh., Web Programming Is Easy, Jakarta : PT. Elex Media Komputindo. 2015.

[2] Ardhana., YM Kusuma. PHP menyelesaikan Web 30 Juta!, Jakarta: Jasakom. 2012.

[3] AS., Rosa dan Shalahuddin., M. Rekayasa Perangkat Lunak Terstruktur Dan Berorientasi Objek. Informatika. Bandung. 2013.

[4] Hakim., Sistem Penilaian dalam Kurikulum 2013: Kajian Dokumen Terhadap Kurikulum 2013. 2013.

[5] Sibero, Alexander F.K., Web Programing Powerpack: MediaKom. 2013.

[6] Sutabri, Tata., Analisis Sistem Informasi. Yogyakarta: Andi. 2012.

[7] Hutahaean, J., Konsep Sistem Informasi. Yogyakarta: CV. Budi Utama. 2014.

[8] Antonio, H., \& Safriadi, N.,. Rancang Bangun Sistem Informasi Administrasi. Informatika. 2012.

[9] Febrian, Jack., Menggunakan Internet, Bandung :Informatika. 2010.

[10] Comminity,. Langkah Muda Menjadi Web Master, Jakarta : Mediakita. 2011.

[11] Indrajani., Pengantar Sistem Basis Data Case Study All In One, Jakarta : ElexMedia Komputindo. 2014.

[12] Rohy., PHP pemograman web!, Jakarta: Jasakom. 2015.

[13] Jogiyanto, 2010. Analisis dan Desain Sistem Informasi, Yogyakarta :Penerbit Andi.

[14] Jakung, L. K., Aplikasi Penjualan Pada Butik Sally Lovely Berbasis Web Menggunakan Program PHP. 2013. 